\title{
Capillary Endothelial Thrombomodulin Expression and Fibrin Deposition in Rats with Continuous and Bolus Lipopolysaccharide Administration
}

\author{
Yasuji Terada, Yutaka Eguchi, Shuichi Nosaka, Toshinari Toba, Tatsuo Nakamura, \\ and Yasuhiko Shimizu
}

Department of Thoracic Surgery (YT), Nagahama City Hospital, Nagahama, Intensive Care Unit (YE, SN), Shiga University of Medical Science, Otsu, and Department of Bioartificial Organs (TT, TN, YS), Institute for Frontier Medical Sciences, Kyoto University, Kyoto, Japan

SUMMARY: We studied capillary endothelial injury, as demonstrated by fibrin deposition and changes in thrombomodulin (Tm) expression, in rats receiving continuous or bolus iv lipopolysaccharide (LPS). Rats were continuously infused with iv LPS (0.1, 0.2 , 0.5 , or $1.0 \mathrm{mg} / \mathrm{kg} / \mathrm{hr}$ ) for up to 6 hours. Others were given a bolus iv dose of LPS $(20 \mathrm{mg} / \mathrm{kg})$, and then the same dose of saline as a continuous infusion was administered for up to 3 hours. Harvested lungs, livers, and kidneys were examined immunohistochemically for thrombomodulin expression and fibrin deposition. Tm expression began to diminish dose- and time-dependently in lung, liver, and renal peritubular capillaries within 2 to 4 hours of the start of continuous LPS administration (1.0 mg/kg/hr) and had completely disappeared by 3 hours, although Tm remained in the glomerulus. The amount of fibrin deposition observed varied with the organ, dose, and duration of treatment in rats that received continuous LPS administration, but little was deposited in the lung. After bolus LPS administration, Tm in the endothelia of lung, liver, and peritubular capillaries diminished 20 to 40 minutes after treatment and then recovered 120 to 180 minutes after treatment, but the Tm activity of the glomerulus did not change. Fibrin deposition in the capillaries was observed in the liver, glomerulus, and peritubular capillaries, but not in the lung. Endothelial injury by LPS administration is dependent on the dose of LPS and the duration of treatment. The amount of fibrin deposition differs among organs and with the duration of contact between the endothelium and the endotoxin. (Lab Invest 2003, 83:1165-1173).

A cute respiratory distress syndrome (ARDS) is a serious complication of sepsis (Parrillo, 1993; St. John and Dorinsky, 1993) and continues to be associated with a high mortality rate (Ashbaugh et al, 1967; Weiland et al, 1986). Lipopolysaccharide (LPS), a major component of the outer membrane of Gram-negative bacteria, has obvious effects on the pulmonary airways and vasculature in intact animals, and it has been implicated as an important agent in the induction of septic shock and ARDS (Bringham and Meyric, 1986; Sibille and Reynolds, 1990). However, the method of administration ip (Makita et al, 1998), bolus iv (Lutz et al, 1998; Tasaka et al, 1995), venous infusion over 2 hours (Schmidt et al, 1997; Walther et al, 2000), or continuous infusion (Simons et al, 1991) and dose of LPS that are required for endothelial injury vary. We evaluated the effects on the endothelium of LPS given by continuous infusion to rats for different times and at different doses, and compared the effects of these continuous infusions with those of bolus infusion. We investigated the effects of LPS by immunohistochemical staining of thrombo-

DOI: 10.1097/01.LAB.0000080606.96797.A5

Received March 25, 2003.

Address reprint requests to: Dr. Yasuji Terada, Department of Thoracic Surgery, Nagahama City Hospital, 313 Oinui-cho, Nagahama, 5268580, Japan.E-mail: yaterada@ex.biwa.ne.jp modulin (Tm) in the capillary endothelium of the lung, liver, and kidney, and by evaluation of fibrin deposition in the capillaries.

$\mathrm{Tm}$ is an endothelial cell membrane glycoprotein that forms a high-affinity complex with thrombin (Owen and Esmon, 1981) and plays an important role in the downregulation of coagulation (Esmon et al, 1982). Thrombin, a key enzyme in thrombus formation, binds to Tm molecules on the endothelium with very high affinity. After binding to Tm, thrombin fails to act on coagulation factors and platelets. Exposure of cultured endothelial cells to LPS induces a sustained fall in surface Tm activity (Semeraro et al, 1993) and a decrease in levels of Tm mRNA (Kapiotis et al, 1991). One might expect that thrombus formation in septic cases would be caused by endothelial injury, but fibrin deposition and dissolution are reportedly correlated with changes in plasminogen activator mRNA (Yamamoto and Loskutoff, 1996). We used immunohistochemical staining to determine Tm expression in a group of rats given continuous and bolus iv LPS to induce damage to the endothelium; we also examined fibrin deposition in the lung, liver, glomerulus, and peritubular capillary.

\section{Results}

In Experiment 1, microscopic observation of the lung and liver tissue after continuous administration of LPS 
showed that Tm began to disappear from the capillaries in a dose- and time-dependent manner within 2 to 4 hours of the beginning of infusion and had completely disappeared by 3 hours in rats given LPS at 1.0 $\mathrm{mg} / \mathrm{kg} / \mathrm{hr}$ (Table 1). In the kidney, Tm of glomerular endothelium did not diminish at all, but $\mathrm{Tm}$ of the peritubular capillary endothelium disappeared in a dose- and time-dependent manner in a similar way to that in the lung and liver. Small depositions of fibrin in the lung were recognized only at 6 hours in rats given LPS at $1.0 \mathrm{mg} / \mathrm{kg} / \mathrm{hr}$. In the liver, fibrin deposition began to be recognized at 3 hours in rats given LPS at $1.0 \mathrm{mg} / \mathrm{kg} / \mathrm{hr}$. In the kidney, thrombi appeared earlier than in the liver in both the glomerulus and peritubular capillaries (Table 2). In the lung, the capillary and venous endothelia showed intense immunohistochemical staining for $\mathrm{Tm}$ in controls (Fig. 1A). Six hours after the beginning of infusion, the lung tissue of rats given LPS at $1.0 \mathrm{mg} / \mathrm{kg} / \mathrm{hr}$ revealed edematous changes, infiltration of neutrophils in the interstitial spaces, and complete disappearance of Tm (Fig. 1B), but $\mathrm{Tm}$ remained in the large vessels (Fig. $1 \mathrm{C}$ ). In the liver, Tm staining was recognized in the endothelia of the central vein and sinusoid in the control (Fig. 2A). However, 6 hours after the beginning of administration of LPS at $1.0 \mathrm{mg} / \mathrm{kg} / \mathrm{hr}$, Tm remained in the central vein but had disappeared in the sinusoid, which showed enlargement and fibrin deposition (Fig. 2B). The endothelia of the kidney, glomerulus (Fig. 3A), and peritubular capillary (Fig. 3B) showed Tm staining, and the intensity of Tm staining in the peritubular capillary was higher in the cortex than in the medulla, and faintest in the papilla. But after 6 hours of administration of LPS at $1.0 \mathrm{mg} / \mathrm{kg} / \mathrm{hr} \mathrm{Tm}$ remained in the glomerulus but had disappeared in the peritubular capillary, which showed fibrin deposition (Fig. 3C).

In Experiment 2 (bolus LPS administration) the diminution of Tm activity and formation of thrombi differed among organs (Table 3). In the lung, liver, and peritubular capillaries, Tm began to disappear at $20 \mathrm{~min}-$ utes, began to recover at 40 minutes, and had fully recovered at 120 minutes. However, Tm activity in the glomerulus did not change. Fibrin deposition appeared at 10 minutes in the liver, glomerulus, and peritubular capillaries, but no fibrin deposition was apparent in the lung throughout the experiment (Table 4). The Tm staining of the lung capillary endothelium began to fade at 20 minutes after bolus administration (Fig. 4A), began to recover at 40 minutes, and had fully recovered by 120 minutes (Fig. 4B), despite neutrophil infiltration.

\section{Discussion}

We assessed endothelial injury by the immunohistochemical staining of Tm. Staining for Tm revealed that with continuous LPS administration the intensity of injury to the endothelium and the time taken for fibrin deposition to begin varied with the LPS dose and duration of exposure, and with the type of organ. With bolus LPS administration, staining for Tm began to fade in 20 to 40 minutes in the endothelium of the lung, liver, and peritubular capillaries, but Tm activity recovered in 120 to 180 minutes. The Tm content of the glomerulus did not change. Fibrin deposition in capillaries was observed in the liver, glomerulus, and peritubular capillaries, but not in the lung.

LPS has been implicated as an important agent in the induction of ARDS (Bringham and Meyric, 1986;

Table 1. Tm Distribution During Continuous LPS Administration As Shown by Immunohistochemical Staining ${ }^{a}$

\begin{tabular}{|c|c|c|c|c|c|c|}
\hline & $1 \mathrm{hr}$ & $2 \mathrm{hr}$ & $3 \mathrm{hr}$ & $4 \mathrm{hr}$ & $5 \mathrm{hr}$ & $6 \mathrm{hr}$ \\
\hline \multicolumn{7}{|l|}{ Lung } \\
\hline LPS $0.1 \mathrm{mg} / \mathrm{kg} / \mathrm{hr}$ & + & + & + & \pm & \pm & - \\
\hline LPS $0.2 \mathrm{mg} / \mathrm{kg} / \mathrm{hr}$ & + & + & + & \pm & - & - \\
\hline LPS $0.5 \mathrm{mg} / \mathrm{kg} / \mathrm{hr}$ & + & \pm & \pm & - & - & - \\
\hline \multicolumn{7}{|l|}{ Liver } \\
\hline LPS $0.1 \mathrm{mg} / \mathrm{kg} / \mathrm{hr}$ & + & + & + & \pm & \pm & \pm \\
\hline LPS $0.2 \mathrm{mg} / \mathrm{kg} / \mathrm{hr}$ & + & + & \pm & \pm & \pm & \pm \\
\hline LPS $0.5 \mathrm{mg} / \mathrm{kg} / \mathrm{hr}$ & + & \pm & \pm & - & - & - \\
\hline $\begin{array}{l}\text { LPS } 1.0 \mathrm{mg} / \mathrm{kg} / \mathrm{hr} \\
\text { Glomerulus }\end{array}$ & \pm & \pm & - & - & - & - \\
\hline LPS $0.1 \mathrm{mg} / \mathrm{kg} / \mathrm{hr}$ & + & + & + & + & + & + \\
\hline LPS $0.2 \mathrm{mg} / \mathrm{kg} / \mathrm{hr}$ & + & + & + & + & + & + \\
\hline LPS $0.5 \mathrm{mg} / \mathrm{kg} / \mathrm{hr}$ & + & + & + & + & + & + \\
\hline $\begin{array}{l}\text { LPS } 1.0 \mathrm{mg} / \mathrm{kg} / \mathrm{hr} \\
\text { Peritubular capillaries }\end{array}$ & + & + & + & + & + & + \\
\hline LPS $0.1 \mathrm{mg} / \mathrm{kg} / \mathrm{hr}$ & + & + & + & + & + & \pm \\
\hline LPS $0.2 \mathrm{mg} / \mathrm{kg} / \mathrm{hr}$ & + & + & + & + & \pm & \pm \\
\hline LPS $0.5 \mathrm{mg} / \mathrm{kg} / \mathrm{hr}$ & + & + & + & \pm & - & - \\
\hline LPS $1.0 \mathrm{mg} / \mathrm{kg} / \mathrm{hr}$ & + & \pm & - & - & - & - \\
\hline
\end{tabular}

LPS, lipopolysaccharide; Tm, thrombomodulin

${ }^{a} \mathrm{Tm}$ staining was evaluated as follows: less than $30 \%(-)$, from $30 \%$ to $60 \%( \pm)$, and more than $60 \%(+)$. 
Table 2. Fibrin Deposition during Continuous LPS Administration ${ }^{a}$

\begin{tabular}{|c|c|c|c|c|c|c|}
\hline & $1 \mathrm{hr}$ & $2 \mathrm{hr}$ & $3 \mathrm{hr}$ & $4 \mathrm{hr}$ & $5 \mathrm{hr}$ & $6 \mathrm{hr}$ \\
\hline \multicolumn{7}{|l|}{ Lung } \\
\hline LPS $0.1 \mathrm{mg} / \mathrm{kg} / \mathrm{hr}$ & - & - & - & - & - & - \\
\hline LPS 0.2 mg/kg/hr & - & - & - & - & - & - \\
\hline LPS $0.5 \mathrm{mg} / \mathrm{kg} / \mathrm{hr}$ & - & - & - & - & - & - \\
\hline $\begin{array}{l}\text { LPS } 1.0 \mathrm{mg} / \mathrm{kg} / \mathrm{hr} \\
\text { Liver }\end{array}$ & - & - & - & - & - & \pm \\
\hline LPS $0.1 \mathrm{mg} / \mathrm{kg} / \mathrm{hr}$ & - & - & - & - & - & \pm \\
\hline LPS 0.2 mg/kg/hr & - & - & - & \pm & \pm & \pm \\
\hline LPS 0.5 mg/kg/hr & - & - & - & \pm & \pm & + \\
\hline $\begin{array}{l}\text { LPS } 1.0 \mathrm{mg} / \mathrm{kg} / \mathrm{hr} \\
\text { Glomerulus }\end{array}$ & - & - & \pm & \pm & \pm & + \\
\hline LPS $0.1 \mathrm{mg} / \mathrm{kg} / \mathrm{hr}$ & - & - & + & + & + & + \\
\hline LPS $0.2 \mathrm{mg} / \mathrm{kg} / \mathrm{hr}$ & - & - & + & + & + & + \\
\hline LPS $0.5 \mathrm{mg} / \mathrm{kg} / \mathrm{hr}$ & - & + & + & + & + & + \\
\hline $\begin{array}{l}\text { LPS } 1.0 \mathrm{mg} / \mathrm{kg} / \mathrm{hr} \\
\text { Peritubular capillaries }\end{array}$ & + & + & + & + & + & + \\
\hline LPS $0.1 \mathrm{mg} / \mathrm{kg} / \mathrm{hr}$ & - & - & + & + & + & + \\
\hline LPS 0.2 mg/kg/hr & - & - & + & + & + & + \\
\hline LPS $0.5 \mathrm{mg} / \mathrm{kg} / \mathrm{hr}$ & - & + & + & + & + & + \\
\hline LPS $1.0 \mathrm{mg} / \mathrm{kg} / \mathrm{hr}$ & + & + & + & + & + & + \\
\hline
\end{tabular}

LPS, lipopolysaccharide.

${ }^{a}$ Fibrin deposition was evaluated as the number of fields containing fibrin out of 10 randomly selected fields examined microscopically: no field in 10 fields (-), 1 to 4 out of $10( \pm)$, and 5 to $10(+)$.

Sibille and Reynolds, 1990) and has been used in experiments on lung injury. Pulmonary microvascular injury is one of the earliest events in ARDS, and it leads to pulmonary edema through increased permeability (Tate and Repine, 1983; Weiss, 1989). Lung injury models have been produced by the administration of LPS via ip injection (Makita et al, 1998), iv injection (Tasaka et al, 1995; Lutz et al, 1998), intratracheal administration (Kermarrec et al, 1998; Rizoli et al, 1998), or inhalation (Johnston et al, 1998) for several hours. However, most clinical cases have an infectious focus, and in these cases endotoxins are thought to be released continuously to the circulating blood. It is reported that there are the similar mortality rates, but significant differences in the kinetics and magnitude of cytokine production between intraperitoneally injected LPS models and cecal ligation and puncture models in mice (Remick et al, 2000). Thus the LPS administration model does not accurately reproduce the cytokine profile of sepsis. This difference was thought to be due to differences in the endotoxin level in the blood. The LPS concentration in the blood of mice after ip administration was thought to be high at first, but then gradually decreased. However, in the cecal ligation and puncture group, endotoxin was considered to be released continuously and increasingly to the blood. Other models of continuous administration include venous infusion over 2 hours (Schmidt et al, 1997; Walther et al, 2000) and continuous infusion (Simons et al, 1991) for hours. Simons et al made an ARDS model of rat by continuous LPS administration of $0.5 \mathrm{mg} / \mathrm{kg}$ for up to 84 hours via primed pumps placed in a subcutaneous tunnel with a silastic catheter introduced into the right atrium (Simons et al, 1991).

In our experiment, LPS was administered continuously to the rat through the tail vein in different doses by an infusion pump, and the results were compared with those of bolus iv LPS administration. The extent of early endothelial injury from LPS exposure was assessed by the reduction in staining for $\mathrm{Tm}$ on the surface of the endothelium. It has been reported that exposure of cultured endothelial cells to LPS induces a reduction in Tm activity (Semeraro et al, 1993) and a decrease in levels of Tm mRNA (Kapiotis et al, 1991). In reports of immunohistochemical staining for Tm, balloon catheter denudation reduced Tm levels in the endothelium of the rabbit aorta (Fink et al, 1993), and radiation caused a sustained, dose-dependent decrease in microvascular Tm expression in the rat small intestine (Wang et al, 2002). However, in sepsis caused by live Escherichia coli iv infusion over 2 hours in the baboon, Tm expression on endothelial cells 4 hours after the infusion had been completed was reported to be unchanged from that in controls, and down-regulation of $\mathrm{Tm}$ could not be demonstrated with certainty in any vascular bed, suggesting that $\mathrm{Tm}$ regulation in vivo may differ from that in cultured cells (Drake et al, 1993). It has also been reported by Laszik et al (Laszik et al, 1994) that neither Tm antigen nor Tm activity was down-regulated in the glomeruli of Sprague-Dawley rats during endotoxemia and Gramnegative septicemia after bolus administration, and the lungs did not show Tm down-regulation either. Therefore, Laszik et al stated that down-regulation of Tm activity after LPS administration in cultured cells is 

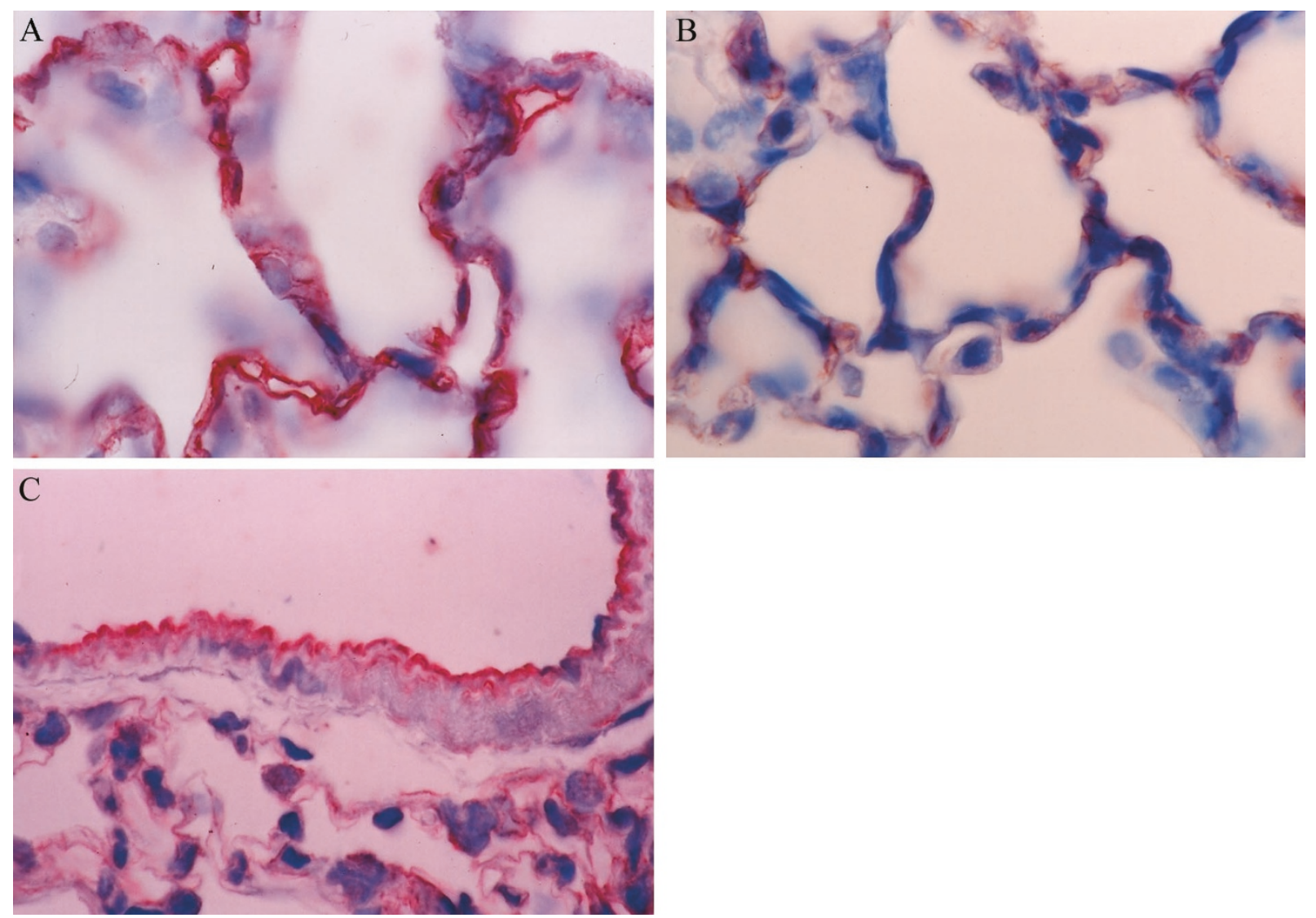

Figure 1.

(A) Intense immunohistochemical staining for thrombomodulin ( $\mathrm{Tm}$ ) occurred in the capillary endothelia of the control lung. (B) Edematous changes, infiltration of neutrophils in the interstitial space, and complete disappearance of Tm in a lung treated with lipopolysaccharide (LPS) at $1.0 \mathrm{mg} / \mathrm{kg} / \mathrm{hr}$ for 6 hours. (C) Tm remains in the large vessels of the lungs of rats treated with LPS at $1.0 \mathrm{mg} / \mathrm{kg} / \mathrm{hr}$ for 6 hours.

different from that in vivo. Our experiment demonstrated that $\mathrm{Tm}$ in the glomerulus was not downregulated by both continuous and bolus LPS administration, although Tm activity in the lung, liver, and peritubular capillaries disappeared in a dose- and time-dependent manner with continuous LPS administration and recovered after initially diminishing with bolus LPS infusion. The reason why Laszik et al (Laszik et al, 1994) did not recognize Tm downregulation was thought to be that they investigated changes only in 30 minutes and 90 minutes in the early phase after bolus LPS administration. Similarly, Drake et al (Drake et al, 1993) infused live E. coli intravenously over 2 hours, but they did not check Tm expression until 4 hours after the infusion had been completed.

The changes of Tm expression in the glomerulus were completely different from those in other organs. Transcriptional expression of Tm in the human kidney is almost the same as in the liver but less than that in the lung (Bajaj et al, 1999). Therefore, endothelial sensitivity to LPS is thought to differ in different organs. With continuous LPS administration, downregulation of $\mathrm{Tm}$ in the lung occurred earlier than in the liver and peritubular capillaries. This is probably because a low dose of iv administered LPS is first absorbed in the lung capillaries, and a lesser concen- tration of LPS then flows to the liver and kidney. However, with bolus administration, Tm expression in these organs diminished almost at the same time, because the dose of LPS was enough for the endothelia of the liver and the kidney. However, the biggest difference between continuous and bolus administration was the recovery of the initially reduced Tm activity in the lung, liver, and peritubular capillaries 120 to 180 minutes after bolus administration. One would expect this endothelial recovery to be caused by the reduction in the level of bolus-administered LPS in the blood. In any investigation of endothelial injury caused by LPS administration, the duration of LPS contact with the endothelium is therefore an important variable.

The time taken for fibrin deposition to begin in the capillaries differed in the liver, glomerulus, and peritubular capillaries after the initiation of continuous LPS administration. In the kidney, fibrin deposition appeared earlier than in the liver, and there was little deposition in the lung. With ip LPS administration in the mouse, Yamamoto and Loskutoff (1996) reported that fibrin was detected only in the kidneys and adrenals and that it was transient. It was not detected in the lung and liver. Further, a significant decrease in urokinase-type plasminogen activator mRNA was correlated with fibrin deposition or dissolution in these 

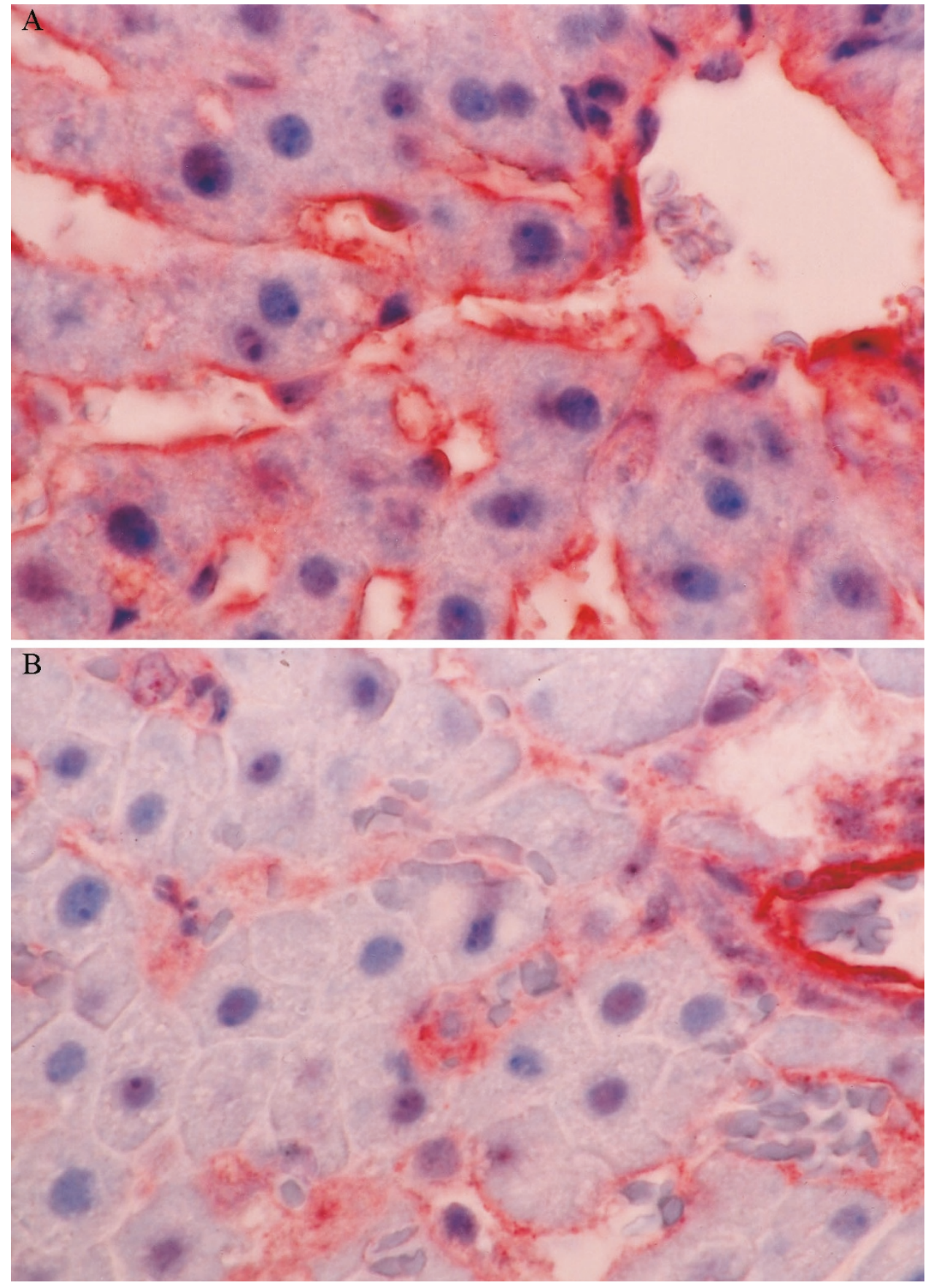

Figure 2.

(A) Thrombomodulin (Tm) staining occurred in the endothelia of the central vein and sinusoid in the livers of controls. (B) Tm remained in the central vein but disappeared in the sinusoid, which showed enlargement and fibrin deposition, in livers of rats treated with lipopolysaccharide at $1.0 \mathrm{mg} / \mathrm{kg} / \mathrm{hr}$ for $6 \mathrm{hours}$.

tissues (Yamamoto and Loskutoff, 1996). In our experiment, the development of fibrin deposition in the liver and kidney depended on the dose of LPS and the method of administration. With our bolus LPS administration, the greatest amount of fibrin was observed at 30 to 40 minutes; the amount of fibrin gradually decreased after 60 minutes, presumably with the recovery of plasminogen activator in local organs. The absence of fibrin deposition in some tissues reflects ongoing local fibrinolysis. Increases in plasminogen activator inhibition and tissue factor gene expression and decreases in urokinase-type plasminogen activator expression are necessary for tissue-specific fibrin deposition (Yamamoto and Loskutoff, 1996). Laszik et al (1994) reported that if Tm remains with fibrin deposition in the glomerulus, then the Tm has had no effect in inhibiting fibrin deposition. Fibrin deposition is considered to be accompanied by endothelial injury in sepsis, but in our experiment fibrin deposition was not always accompanied by a reduction in staining for $\mathrm{Tm}$ that could be considered to represent endothelial injury. We consider that fibrin deposition is not neces- 

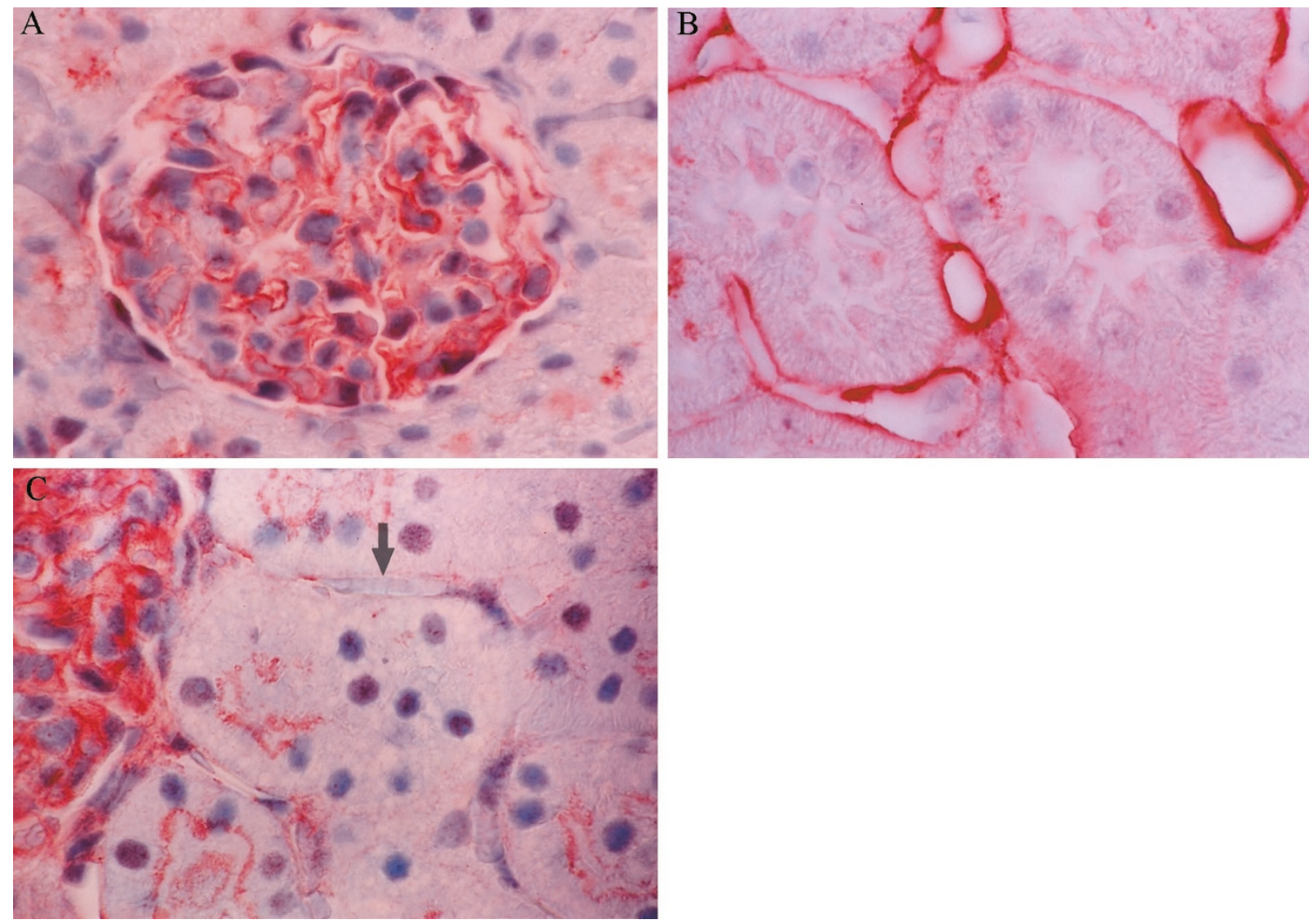

\section{Figure 3.}

(A) Intense immunohistochemical staining for thrombomodulin (Tm) in the renal glomerulus of the control. (B) Intense immunohistochemical staining for Tm in the renal peritubular capillary of the control. (C) In rats treated with lipopolysaccharide at $1.0 \mathrm{mg} / \mathrm{kg} / \mathrm{hr}$ for 6 hours, Tm remained in the glomerulus, but disappeared in the peritubular capillary, which showed fibrin deposition (arrow).

Table 3. Tm Distribution after Bolus Lipopolysaccharide Administration As Shown by Immunohistochemical Staininga

\begin{tabular}{|c|c|c|c|c|c|c|c|}
\hline & $10 \mathrm{~min}$ & $20 \mathrm{~min}$ & $30 \mathrm{~min}$ & $40 \min$ & $60 \mathrm{~min}$ & $120 \min$ & $180 \mathrm{~min}$ \\
\hline Lung & + & - & - & \pm & \pm & + & + \\
\hline Liver & + & \pm & - & - & \pm & + & + \\
\hline Glomerulus & + & + & + & + & + & + & + \\
\hline Peritubular capillaries & + & \pm & - & - & \pm & + & + \\
\hline
\end{tabular}

Tm, thrombomodulin.

${ }^{a} \mathrm{Tm}$ staining was evaluated as follows: less than $30 \%(-)$, from $30 \%$ to $60 \%( \pm)$, and more than $60 \%(+)$.

Table 4. Fibrin Deposition in Bolus Lipopolysaccharide Administration ${ }^{a}$

\begin{tabular}{lccccccc}
\hline & $10 \min$ & $20 \min$ & $30 \min$ & $40 \min$ & $60 \min$ & $120 \min$ & $180 \min$ \\
\hline Lung & - & - & - & - & - & - & - \\
Liver & - & \pm & + & + & + & \pm & \pm \\
Glomerulus & - & \pm & + & + & + & \pm & \pm \\
Peritubular capillaries & - & \pm & + & + & + & \pm & \pm \\
\hline
\end{tabular}

${ }^{a}$ Fibrin deposition was evaluated as the number of fields containing fibrin out of 10 randomly selected fields examined microscopically: no field in 10 fields (-), 1 to 4 out of $10( \pm)$, and 5 to $10(+)$.

sarily essential as an indicator of endothelial injury in this murine model of sepsis.

In conclusion the changes in Tm activity and fibrin deposition in the endothelium of rats given LPS varied according to dose, time, method of LPS administra- tion, and the type of organ. Bolus administration of LPS would be useful for making a shock model, but to provoke endothelial injury, it is essential that the endotoxin is in contact with the endothelium for an adequate period of time. 

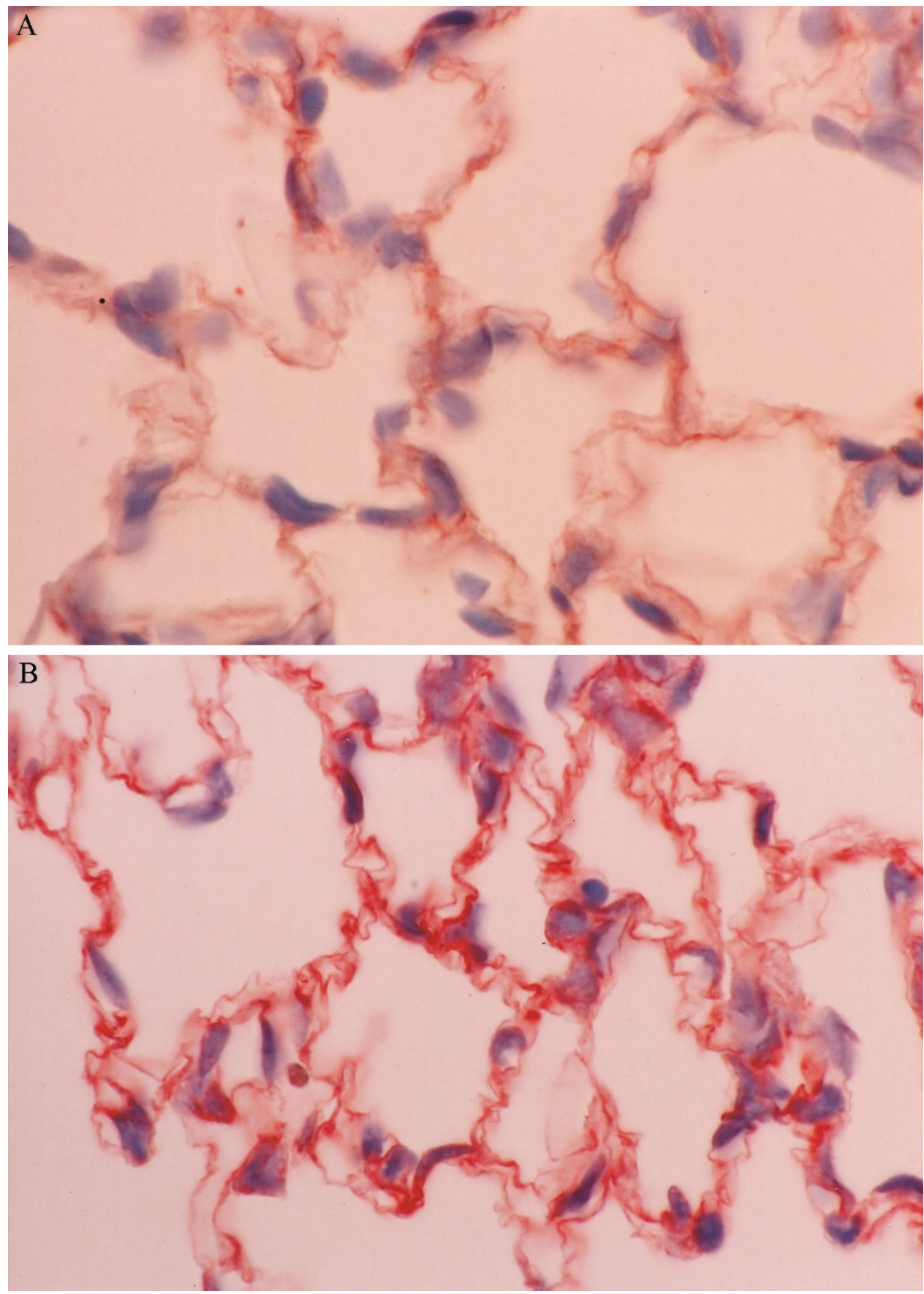

Figure 4.

(A) Thrombomodulin (Tm) staining began to diminish in capillary endothelia of the lung 20 minutes after bolus lipopolysaccharide (LPS) administration at $20 \mathrm{mg} / \mathrm{kg}$. (B) By 120 minutes after bolus administration of LPS at $20 \mathrm{mg} / \mathrm{kg}$, Tm staining had fully recovered, despite neutrophil infiltration.

\section{Materials and Methods}

\section{Animals}

All experiments were performed on pathogen-free male Sprague-Dawley rats weighing 300 to $350 \mathrm{~g}$. All procedures described in this article were performed in accordance with the Animal Experiment Guidelines of Kyoto University (1989), and the care and handling of the animals were in accordance with the guidelines of the National Institutes of Health. All animals were kept on a diet of standard rat chow and water ad libitum until the day before the experiment. Food was withheld from all animals for 4 hours before the experiment, and free access to water was maintained.

\section{Reagents}

LPS (0127: B8), purchased from Difco Laboratories (Detroit, Michigan), was dissolved in physiologic saline at concentrations of $5 \mathrm{mg} / \mathrm{mL}$ and stored at $-80^{\circ} \mathrm{C}$ in small aliquots. On the day of use, dissolved LPS was used for bolus injection and adjusted to concentra- 
tions of 0.01 to $0.1 \mathrm{mg} / \mathrm{ml}$ in saline for continuous administration.

\section{Experimental Protocol}

Experiment 1. In each rat the infusion catheter (Suflo $24 \mathrm{G} \times 3 / 4$ inch; Terumo Medical Corporation, Tokyo, Japan) was introduced into the lateral tail vein under light anesthesia with diethyl ether. The infusion line was fixed to the tail, and each animal was conscious and freely moving at all times throughout the procedure. LPS diluted in saline was continuously infused at $10 \mathrm{ml} / \mathrm{kg} / \mathrm{hr}$ with an infusion pump (STC-525, Terumo Medical Corporation) for up to 6 hours. LPS was diluted to administer $0.1,0.2,0.5$, or $1.0 \mathrm{mg} / \mathrm{kg} / \mathrm{hr}$. Control rats were injected with the same volume of saline for up to 6 hours. At 1, 2, 3, 4, 5, or 6 hours after the beginning of infusion, animals were anesthetized by ip injection of $50 \mathrm{mg} / \mathrm{kg}$ pentobarbital sodium (Nembutal Abbott Laboratories, North Chicago, Illinois), and the lungs, livers, and kidneys were harvested for examination by hematoxylin and eosin staining and immunohistochemical assessment of Tm expression.

Experiment 2. After the iv line was introduced in the same way as in experiment 1 , bolus iv administration of LPS $(20 \mathrm{mg} / \mathrm{kg})$ at a concentration of $5 \mathrm{mg} / \mathrm{ml}$ in saline was performed. The same dose of saline as that used in Experiment 1 (10 ml/kg/hr) was continuously infused with an infusion pump, and the lungs, livers, and kidneys were harvested at 10, 20, 30, 40, 50, 60, 120 , or 180 minutes in the same manner as in Experiment 1.

\section{Histopathologic Examination}

The right lower lobe of the lung, as well as the left lobe of the liver and one kidney, were immediately fixed in $4 \%(\mathrm{w} / \mathrm{v})$ paraformaldehyde in $0.1 \mathrm{M}$ phosphate buffer $(\mathrm{pH} 7.4)$ at $4^{\circ} \mathrm{C}$ for 8 hours, and then dehydrated and embedded in paraffin. Serial sections were cut at 4- $\mu \mathrm{m}$ thickness, mounted on poly-L-lysine-coated slides, and subjected to hematoxylin and eosin staining, phosphotungstic acid hematoxylin staining, and immunohistochemical staining.

Polyclonal antibody against Tm was provided by Kokusai Shiyaku Company (Kobe, Japan), and immunohistochemical staining was performed with a Histofine SAB-PO kit (Nichirei, Tokyo, Japan). Deparaffinized sections were rinsed with 3\% hydrogen peroxide in methanol at room temperature for 10 minutes. To unmask tissue antigens, sections were digested with $0.3 \%(\mathrm{w} / \mathrm{v})$ pepsin (Sigma, St. Louis, Missouri) in $0.01 \mathrm{~N} \mathrm{HCl}$ for 15 minutes at room temperature. The sections were incubated with $10 \%$ normal goat serum in PBS (PBS: $0.01 \mathrm{M}, \mathrm{pH}$ 7.4) for 30 minutes, followed by incubation at $4^{\circ} \mathrm{C}$ overnight with primary antibody, which was diluted to $10 \mu \mathrm{g} / \mathrm{mL}$ with PBS containing $0.1 \%$ normal goat serum. After the sections had been washed with $0.2 \%$ Triton X-100 in PBS (twice for 3 minutes), biotinylated secondary antibody (Histofine SAB-PO kit; Nichirei) was added, and they were incubated for 20 minutes at room temperature. The sections were then washed again with $0.2 \%$ Triton $\mathrm{X}-100$ in PBS (twice for 3 minutes) and then incubated with streptavidin-peroxidase conjugate (Histofine SAB-PO kit; Nichirei). After the sections had been washed with $0.2 \%$ Triton X-100 in PBS (twice for 3 minutes), visualization was achieved with $\mathrm{H}_{2} \mathrm{O}_{2}$-supplemented amino-ethylcarbazole chromogen (Ejiri et al, 1996). The sections were counterstained with hematoxylin and mounted. Control sections were incubated with nonimmune $\lg \mathrm{G}$ in place of the primary antibody. Samples were analyzed under oil at $\times 500$ magnification by an observer who did not know the animal's group assignment.

\section{Histologic Evaluation of Thrombomodulin and Fibrin Deposition}

Tm staining was evaluated in the following way: $<30 \%$ $(-)$, from $30 \%$ to $60 \%( \pm)$, and more than $60 \%(+)$. Fibrin deposition was evaluated under the microscope by the number of fields in which it was present out of 10 randomly selected fields: no field in 10 fields $(-), 1$ to 4 out of $10( \pm)$, and 5 to $10(+)$.

\section{References}

Ashbaugh DG, Bigelow DB, Petty TL, and Levine BE (1967). Acute respiratory distress in adults. Lancet 2:319-323.

Bajaj MS, Kuppuswamy MN, Manepalli AN, and Bajaj SP (1999). Transcriptional expression of tissue factor pathway inhibitor, thrombomodulin and von Willebrand factor in normal human tissues. Thromb Haemostasis 82:1047-1052.

Bringham KL and Meyric B (1986). Endotoxin and lung injury. Am Rev Respir Dis 133:913-927.

Drake TA, Cheng J, Chang A, and Taylor FB, Jr (1993). Expression of tissue factor, thrombomodulin, and E-selectin in baboons with lethal Escherichia coli sepsis. Am J Pathol 142:1458-1470.

Ejiri S, Eguchi Y, Kishida A, Xie G, Kurumi Y, and Kodama M (1996). Protective effect of a prostaglandin I2 analogue on grafted livers subjected to in situ warm ischemia in porcine orthotopic liver transplantation: Immunohistochemical analysis of thrombomodulin. Transplant Proc 28:1086-1088.

Esmon NW, Owen WG, and Esmon CT (1982). Isolation of a membrane-bound cofactor for thrombin-catalyzed activation of protein C. J Biol Chem 257:859-864.

Fink LM, Eidt JF, Johnson K, Cook JM, Cook CD, Morser J, Marlar R, Collins CL, Schaefer R, Xie SS, Hsu SM, and Hsu PL (1993). Thrombomodulin activity and localization. Int J Dev Biol 37:221-226.

Johnston CJ, Finkelstein NJ, Gelein R, and Oberdorster G (1998). Pulmonary cytokine and chemokine mRNA levels after inhalation of lipopolysaccharide in C57BL/6 mice. Toxicol Sci 46:300-307.

Kapiotis S, Besemer J, Bevec D, Valent P, Bettelheim P, Lechner K, and Speiser W (1991). Interleukin-4 counteracts pyrogen-induced downregulation of thrombomodulin in cultured human vascular endothelial cells. Blood 78:410-415.

Kermarrec N, Chollet MS, Beloucif S, Faivre V, Gougerot PMA, and Payen DM (1998). Alveolar neutrophil oxidative 
burst and beta2 integrin expression in experimental acute pulmonary inflammation are not modified by inhaled nitric oxide. Shock 10:129-134.

Laszik Z, Carson CW, Nadasdy T, Johnson LD, Lerner MR, Brackett DJ, Esmon CT, and Silva FG (1994). Lack of suppressed renal thrombomodulin expression in a septic rat model with glomerular thrombotic microangiopathy. Lab Invest 70:862-867.

Lutz C, Picone A, Gatto LA, Paskanik A, Landas S, and Nieman GF (1998). Exogenous surfactant and positive endexpiratory pressure in the treatment of endotoxin-induced lung injury. Crit Care Med 26:1379-1389.

Makita H, Nishimura M, Miyamoto K, Nakao T, Tanino Y, Hirokawa J, Nishihira J, and Kawakami Y (1998). Effect of anti-macrophage migration inhibitory factor antibody on lipopolysaccharide-induced pulmonary neutrophil accumulation. Am J Respir Crit Care Med 158:573-579.

Owen WG and Esmon CT (1981). Functional properties of an endothelial cell cofactor for thrombin-catalyzed activation of protein C. J Biol Chem 256:5532-5535.

Parrillo JE (1993). Pathogenetic mechanisms of septic shock. N Engl J Med 328:1471-1477.

Remick DG, Newcomb DE, Bolgos GL, and Call DR (2000). Comparison of the mortality and inflammatory response of two models of sepsis: Lipopolysaccharide vs. cecal ligation and puncture. Shock 13:110-116.

Rizoli SB, Kapus A, Fan J, Li YH, Marshall JC, and Rotstein OD (1998). Immunomodulatory effects of hypertonic resuscitation on the development of lung inflammation following hemorrhagic shock. J Immunol 161:6288-6296.

Schmidt H, Schmidt W, Muller T, Bohrer H, Gebhard MM, and Martin E (1997). N-acetylcysteine attenuates endotoxininduced leukocyte-endothelial cell adhesion and macromolecular leakage in vivo. Crit Care Med 25:858-863.

Semeraro N, Triggiani R, Montemurro P, Cavallo LG, and Colucci M (1993). Enhanced endothelial tissue factor but normal thrombomodulin in endotoxin-treated rabbits. Thromb Res 71:479-486.
Sibille Y and Reynolds HY (1990). Macrophages and polymorphonuclear neutrophils in lung defense and injury. Am Rev Respir Dis 141:471-451.

Simons RK, Maier RV, and Chi EY (1991). Pulmonary effects of continuous endotoxin infusion in the rat. Circ Shock 33:233-243.

St. John RC and Dorinsky PM (1993). Immunologic therapy for ARDS, septic shock, and multiple organ failure. Chest 103:932-943.

Tasaka S, Ishizaka A, Urano T, Sayama K, Sakamaki F, Nakamura H, Terashima T, Waki Y, Soejima K, Oyamada Y, Fujishima S, and Kanazawa M (1995). BCG priming enhances endotoxin-induced acute lung injury independent of neutrophils. Am Rev Respir Crit Care Med 152:1041-1049.

Tate RM and Repine JE (1983). Neutrophils and the adult respiratory distress syndrome. Am Rev Respir Dis 128:552559.

Walther A, Weihrauch M, Schmidt W, Gebhard MM, Martin E, and Schmidt H (2000). Leukocyte-independent plasma extravasation during endotoxemia. Crit Care Med 28:29432948.

Wang J, Zheng $\mathrm{H}$, Ou X, Fink LM, and Hauer-Jensen M (2002). Deficiency of microvascular thrombomodulin and up-regulation of protease-activated receptor-1 in irradiated rat intestine: Possible link between endothelial dysfunction and chronic radiation fibrosis. Am J Pathol 160:2063-2072.

Weiland JE, Davis WB, Holter JF, Mohammed JR, Dorinsky PM, and Gadek JE (1986). Lung neutrophils in the adult respiratory distress syndrome: Clinical and pathologic significance. Am Rev Respir Dis 133:218-225.

Weiss ST (1989). Tissue destruction by neutrophils. N Engl J Med 320:365-376.

Yamamoto K and Loskutoff DJ (1996). Fibrin deposition in tissues from endotoxin-treated mice correlates with decreases in the expression of urokinase-type but not tissuetype plasminogen activator. J Clin Invest 97:2440-2451. 